\title{
Development of a method for assessing operating room management based on diagnosis procedure combination $E$ - and F-file data
}

\author{
M Tanaka*, M Sekimoto and Y Imanaka
}

Address: Department of Healthcare Economics and Quality Management, School of Public Health, Graduate School of Medicine, Kyoto University, Kyoto, Japan

* Corresponding author

from 25th Patient Classification Systems International (PCSI) Working Conference

Fukuoka, Japan. II-I 4 November 2009

Published: 5 November 2009

BMC Health Services Research 2009, 9(SuppI I):A8 doi:10.I 186/1472-6963-9-SI-A8

This abstract is available from: http://www.biomedcentral.com/I472-6963/9/SI/A8

(c) 2009 Tanaka et al; licensee BioMed Central Ltd.

\section{Introduction}

Due to rising health costs, hospitals are making efforts to assess and improve management efficiency. However, at present, Japanese hospitals rely on individual assessment methods. Due to the lack of a common method of assessment - based on standardized data available from all hospitals - meaningful comparisons cannot be conducted. The objectives of this study were to develop a method of assessing OR management based on standardized administrative data, and to apply this method in assessing and comparing OR efficiencies in a multi-institutional setting.

\section{Methods}

DPC (Diagnosis Procedure Combination) is a patient classification system in Japan. DPC data E and F files contain detailed information such as general anesthesia duration, and dosages for all medication prescribed. We obtained patient data from 133 hospitals, between April 2006 and March 2008, from the specific components of the DPC database known as the $\mathrm{E}$ and $\mathrm{F}$ files.

As possible indicators for assessing operation management, we offer the following variables. Using data from the $\mathrm{E}$ and F files of the DPC database, we calculated:

-x) Procedural fee per OR per month

- a) Number of operations per OR per month
- b) Procedural fee per operation

- c) Total utilization times of each OR per month

- d) Procedural fee per OR per hour

In order to take into account hospital variations while analyzing reimbursement, we carried out a multiple linear regression analysis at the hospital level. The dependent variable was the procedural fee per OR per month, and the independent variables were the number of surgeons per OR and the total number of beds.

Next, for surgery volume, another multiple linear regression analysis was conducted. The dependent variable was the number of operations per OR per month, and the independent variables were the number of surgeons per $\mathrm{OR}$, and the total number of beds.

Finally, we conducted a multi-institutional comparison of expected and observed values for the dependent variables from both regression models in 133 hospitals.

\section{Results}

We show the results of descriptive statistics for the following:

- Procedural fee per OR per month 
- Number of operations per OR per month

- Procedural fee per operation

- Total utilization time of each OR per month

- Procedural fee per OR per hour

There were large inter-hospital variations seen in all five of these indicators. The mean procedural fee per OR per month was found to be US $\$ 76,516$ (SD: US $\$ 31,145$; Range: US $\$ 11,857$-US $\$ 195,546)$. There was an observed mean of 46 operations per OR per month (SD: 16 operations; Range: 10-107 operations).

According to the results of our regression analyses, we found that the number of surgeons per OR, as well as the total number of beds in each hospital, was significantly and positively associated with our operation management assessment indicators of procedural fee per OR per month, and the number of operations per OR per month.

Using the expected values of the dependent variables from the regression models, we conducted a comparison of the observed/expected $(\mathrm{O} / \mathrm{E})$ ratios of each hospital, as well as their respective residual values relative to an $\mathrm{O} / \mathrm{E}$ ratio of 1. This allowed for the assessment of the relative performance of each hospital.

\section{Conclusion}

The OR management assessment method, which is based on standardized DPC data, allows for meaningful multiinstitutional comparisons. Comparisons of the expected and observed values of the indicators, based on these data, may provide a greater insight into the target of the fee, as well as the number of surgical operations occurring at each hospital (after taking into account inter-hospital variations). Therefore these comparisons may be useful as a tool in target management.
Publish with Biomed Central and every scientist can read your work free of charge

"BioMed Central will be the most significant development for disseminating the results of biomedical research in our lifetime. " Sir Paul Nurse, Cancer Research UK

Your research papers will be:

- available free of charge to the entire biomedical community

- peer reviewed and published immediately upon acceptance

- cited in PubMed and archived on PubMed Central

- yours - you keep the copyright

Submit your manuscript here:

http://www.biomedcentral.com/info/publishing_adv.asp 